\title{
Analysis of dynamic parameters of the KY-crystallization process
}

\author{
Ie.V.Kryvonosov, L.A.Lytvynov \\ Institute for Single Crystals, STC "Institute for Single Crystals" National \\ Academy of Sciences of Ukraine, \\ 60 Nauky Ave., 61001 Kharkiv, Ukraine
}

Received November 16, 2015

\begin{abstract}
The Kyropoulos method is an efficient means for the growth of large high-quality sapphire. The main drawback of this method is the absence of information about the growth rate and geometrical size of the growing crystal during the technological process. Described in the present work is a method for analyzing the dynamic characteristics of the real crystallization process. The method is based on the readings of the growing crystal weight sensor, and on a virtual image of the technological process, assumed that the crystallization interface has a conical shape characterized by a varying angle at the cone vertex.
\end{abstract}

Keywords: Kyropoulos method, growing crystal, sapphire.

Метод Киропулоса - перспективный метод для выращивания крупных монокристаллов сапфира высокого качества. Основной недостаток метода - отсутствие информации о динамических характеристиках процесса кристаллизации. В работе описан метод анализа динамических характеристик процесса реальной кристаллизации основанный на показаниях датчика веса растущего кристалла и анализе виртуального изображения технологического процесса. Предполагается, что интерфейс кристаллизации имеет коническую форму, характеризуемую изменяющимся углом вершины конуса.

Аналіз динамічних параметрів процесу КY-кристалізації. Є.В.Кривоносов, Л.А.Літвинов.

Метод Кіропулоса - перспективний метод для вирощування крупних монокристалів сапфіру високої якості. Основний недолік метода - відсутність інформації про динамічні характеристики процесу кристалізації. У роботі описано метод аналізу динамічних характеристик процесу реальної кристалізації, обгрунтований свідченнями датчика ваги кристала, що росте i аналізі віртуального зображення технологічного процесу. Передбачається, що інтерфейс кристалізації має конічну форму, яка характеризується змінним кутом при вершині конуса.

\section{Introduction}

The Kyropoulos (KY) method is an efficient means for the growth of large highquality sapphire. The main drawback of this method is the absence of information about the dynamic parameters of the growth process. Technologists try to overcome this drawback by using the methods of analytical calculations of the thermal conditions of crystallization and experimental choice of optimum growth conditions.
There have been developed computer programs for calculation and numerical simulation of temperature fields in the growth zone formed by different systems of reflecting and heat-insulating shields [1-6]. At constructing of technological equipment such programs make it possible to calculate global heat exchange in the whole of the crystallization chamber and heat transfer in the growth zone taking into account laminar gas flow and convection of the melt in 


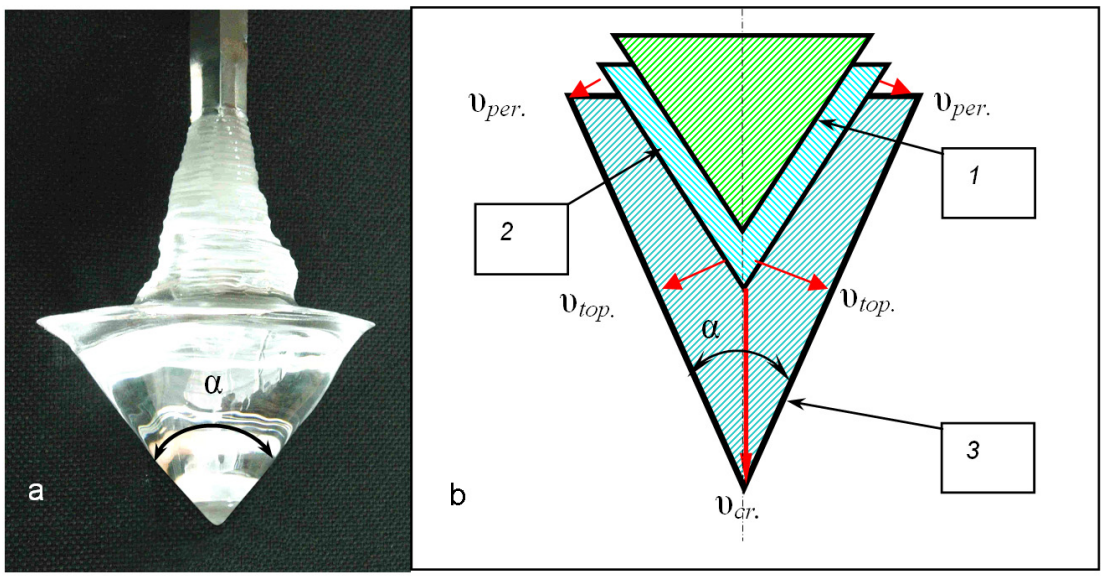

Fig. 1. The shape of crystallization front (CF) of a growing sapphire on initial crystallization stage by the KY-method (a) and influence of the angle $\alpha$ on the normal constituent of the crystallization speed (b): - CF moving from pos. 1 to pos.2 with the permanent value of the CFS-parameter (angle $\alpha)$; - CF moving from pos.2 to pos.3 with decrease of the CFS-parameter value.

the crucible. They also allow to estimate the influence of the design of the thermal unit and thermal conditions on mass transfer in the melt and the formation of thermoelastic stresses in the growing crystal. However, the programs do not consider the dynamics of the change in the parameters of the real crystallization process. Only after solving this problem, the process of crystal growth will be controlled and optimized.

Quality of growing crystal substantially depends on the dynamics of the change of the crystallization front, the change of the growing crystal diameter and of the crystallization rate during the whole of the growth process. The present work considers a method for estimation of the main dynamic parameters of the crystallization process [7].

\section{Signature of the KY-method}

In the process of crystal growth by KYmethod, the crystallization front shape changes depending on the configuration of the thermal field of the used growth unit. This substantially influences on the form of growing crystal and the crystallization rate. Therefore the control of crystallization front is a necessary condition for optimization of crystallization process. As a result of degradation of construction elements of thermal unit in the process of exploitation, the thermal characteristics of the crystallizer constantly vary from a process to the process, and such variations are of accumulative character. Therefore, after several crystallization cycles the technological conditions must be corrected.
For optimization of crystallization process the method of virtual technological process simulation is offered for the desired conditions (the crucible dimensions and shape, the amount of the raw material, the crystallization front shape, the rates of crystallization and of pulling the crystal from the melt). Information about the dynamics of change of main technological parameters is the result of the simulation: geometrical sizes and weight of the growing crystal, the crystallization front shape, the movement velocity of the crystallization interface, and also a low of level melt changing in the crucible.

The dynamic parameters of the real crystallization process are determined from the virtual image of the process. In its turn, the virtual image is calculated on the assumption that the shape of the crystallization front is conical with a varying angle $\alpha$ at the vertex. It is possible the angle $\alpha$ to use as the parameter of a crystallization front shape (CFS-parameter). This is a close approximation of the real shape of the crystallization front of sapphire grown by KY-method (Fig. 1a) that makes it possible to describe the said dynamic parameter using relatively simple mathematical expressions. An adequate correspondence of the real process to its virtual image is realized in the case when the profile and dynamics of the rise of the real crystal weight exactly correspond to those of the virtual crystal.

For optimization of technology of a single crystals growth is important to know the micro kinetics of crystallization. For the Czochralski and HDS methods the form of 


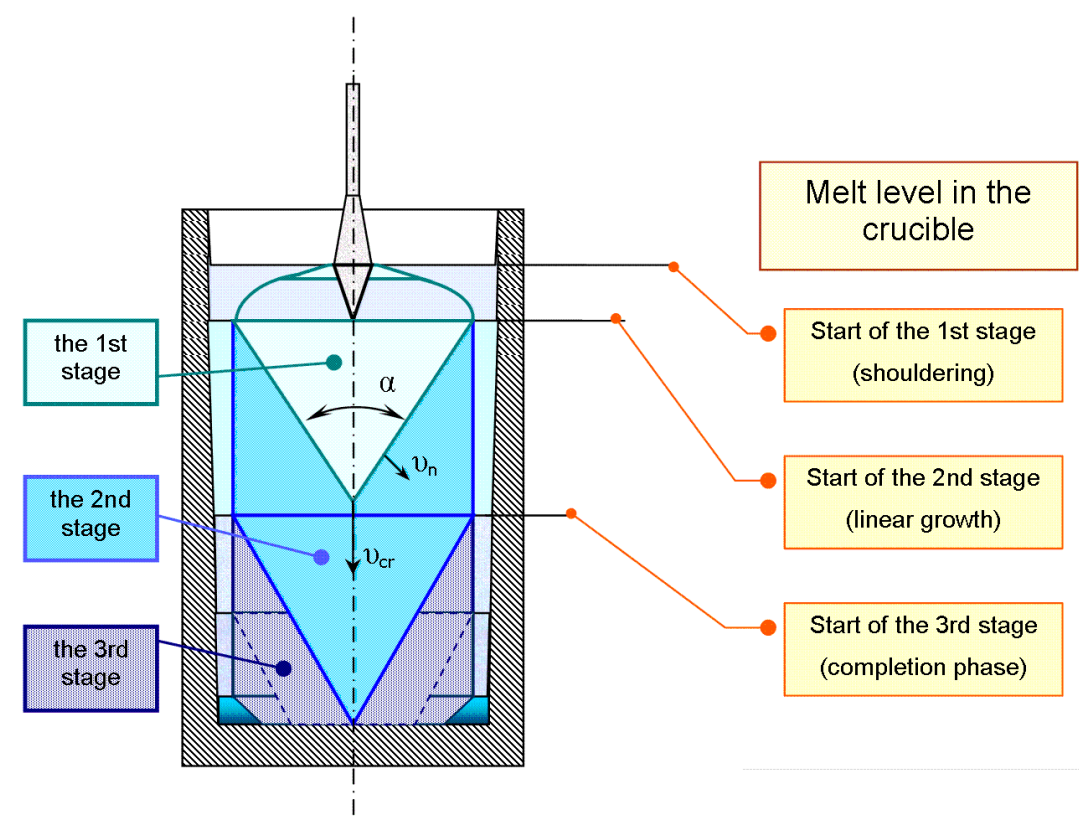

Fig. 2. Characteristic stages of the process of crystallization by the KY-method.

crystallization front is invariable during growth of crystal, but at KY-method the crystallization front can considerably to change the form. The uneven local change of crystallization speed on the separate areas of the crystal-melt interface can become the reason of structural defects formation in a crystal and be conducive to a entrapment by the crystallization front of gases micro bubbles from melt. Hereby the decrease of the CFS-parameter value is related to decline of the normal crystallization speed on the periphery $\left(v_{p e r}\right)$ and accordingly by the increase at top $\left(v_{t o p}\right)$ of the conical shape crystallization front (Fig. 1b).

Some researchers tried to calculate the microkinetics of sapphire crystallization by the methods of mathematical modeling [8]. The got data analysis allows to do the conclusion about uneven speed of crystallization on different areas of the crystallization front. However this not makes it possible to bind the got results to description of the really grown crystals for lack of information about the dynamics of change of form of the crystallization front.

\section{The simulation procedure of technological process}

The process of crystallization comprises three stages (Fig. 2):

- Stage 1: radial growth, i.e. the increase of the crystal diameter from the one of the seed up to the maximal value defined by the crucible dimensions and the crystal pulling rate. At this stage there take place changes of the crystallization front shape (namely, the depth of the immersion of the part of the crystal into the melt and the angle $\alpha$, which defines of the crystallization front shape).

- Stage 2: the increase of the crystal length at slightly changing crystal diameter and the crystallization front shape.

- Stage 3: the crystal length continues to rise even at slightly changing crystal diameter and varying shape of the crystallization front.

The crystal quality is defined mainly by the dynamic characteristics of the Stage 1 and partially by those of Stage 2 . To beginning of Stage 3 the vertex of the crystallization front reaches the crucible bottom and the crystal structure quality is already formed, thereat the crystallization conditions remain practically unchanged. Therefore, optimization of the whole of the crystallization process is bound up with the analysis of the first two stages.

A growing crystal is well screened, the crystallization front is in melt and its real visualization is practically impossible. The virtual-image of the grown crystal, by the "Dynamic calculator" program simulated, allows estimating influence of the growth kinetics on quality of the crystals.

As a rule, the changes of the growing crystal weight are registered during the whole of the crystallization cycle. The profile of the grown crystal is digitized by one of the existing methods (e.g. photometry). 
The data on the dynamics of the increase of the crystal weight and on its shape are used to calculate the virtual image of the crystallization process which allows to establish the dynamics of the change of the longitudinal crystal growth rate and the angle $\alpha$.

The main task of digitization of the crystal profile was to present the digital and graphical dependence of the crystal diameter on its height in the Microsoft Excel format. For this purpose the grown crystal was photographed frontally at several aspect angles by turning it about the growth axis alongside a metrical ruler.

Each image of the crystal was fragmented into rectangular sections with a height of $1.5-2.0 \mathrm{~mm}$ and a width corresponding to the crystal diameter at the given length, in the format of the program CorelDraw using the button bar. Thereat, the image scale of the photograph corresponded to the scale of the format of the program CorelDraw, that made it possible to digitize the profile of each image of the photographed crystal. The digitized profile of the grown crystal was obtained by averaging the digitization data for all the images of the crystal. The criterion of the digitization accuracy is the correspondence of the real weight of the grown crystal to its weight calculated according to the data for the digitized profile.

Using the data of photometry and dynamics of the changes in the readings of the growing crystal weight sensor, the virtual image of the crystallization process was simulated on the basis of the geometrical crystal growth model (Fig. 3). The whole crystallization process was considered to be a set of elementary steps of a preset duration $(\tau)$. Within each step the axial crystallization rate $\left(v_{c r}\right)$ and the CFS parameter (the angle $\alpha$ ) remained constant and changed at the transition to the next step. The initial data for the simulation included the geometrical dimension of the crucible, the amount of the charged raw material, the dynamics of the change in the rate of pulling the crystal from the melt $\left(v_{p u l}\right)$ during the process of crystallization, as well as the readings of the crystal weight sensor during the technological process.

The readings of the crystal weight sensor vary within an elementary crystallization step due to the changes in the volume of the part of the crystal over the melt and in the part of the crystal immersed into the melt. An elementary crystallization step includes two successive stages: pulling of the crys-

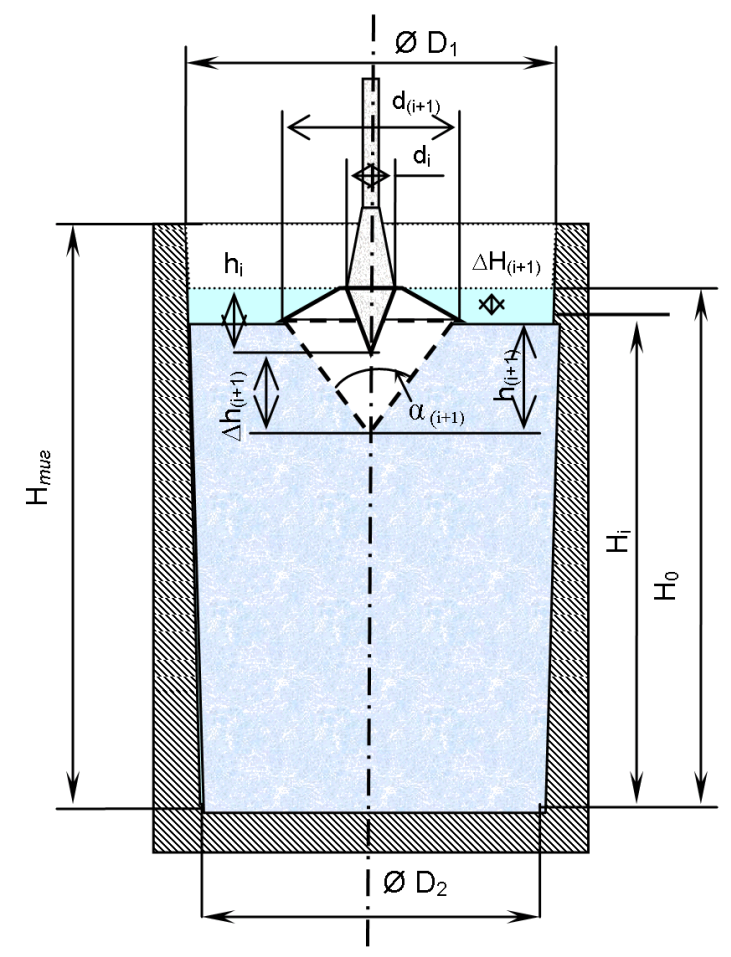

Fig. 3. Geometrical model of crystal growth by the KY-method.

tals from the melt without crystallization and crystallization without crystal pulling. Realization of each stage causes changes in the level of the melt in the crucible, in the volume of the crystal above the melt and in the melt, as well in the value of Archimedean force, affection the growing crystal.

At the stage of crystal pulling the length of the part of the crystal over the melt increases, whereas the length to the part of the crystal immersed into the melt diminishes by the value $\delta L_{(i+1)}$ :

$$
\delta L_{(i)}=\frac{\rho_{m} \cdot R_{(i-1)}^{2} \cdot v_{p u l} \cdot \tau}{\rho_{m} \cdot R_{(i-1)}^{2}-\rho_{c r} \cdot r_{(i-1)}^{2}} .
$$

On the basis of the geometrical model and taking into account Archimedean force, the changes in the readings of the crystal weight sensor during one elementary crystallization step $\Delta G_{(i+1)}$ can be expressed as

$$
\begin{aligned}
& \Delta G_{(i)}=\frac{\pi \cdot \rho_{c r}}{3} \cdot\left\{\left[\Delta H_{(i)} \cdot\left(r_{(i)}^{2}+r_{(i)}^{*} \cdot r_{(i)}+\left\{r_{(i)}^{*}\right\} 2+\right)\right.\right. \\
& \left.\left.\quad+\frac{\rho_{c r}-\rho_{m}}{\rho_{c r}}\left(r_{(i)}^{2} \cdot h_{(i)}-r_{(i)}^{*} \cdot h_{(i)}^{*}\right)\right]+3 \cdot r_{(i)}^{*} \cdot \delta L_{(i)}\right\} \\
& \text { where } r_{(i)}^{*}=r_{(i-1)} \cdot\left(\operatorname{ctg} \frac{\alpha_{(i-1)}}{2} / \operatorname{ctg} \frac{\alpha_{(i)}}{2}\right)^{1 / 3} \text { and }
\end{aligned}
$$


The crystal shape, $\mathrm{mm}$
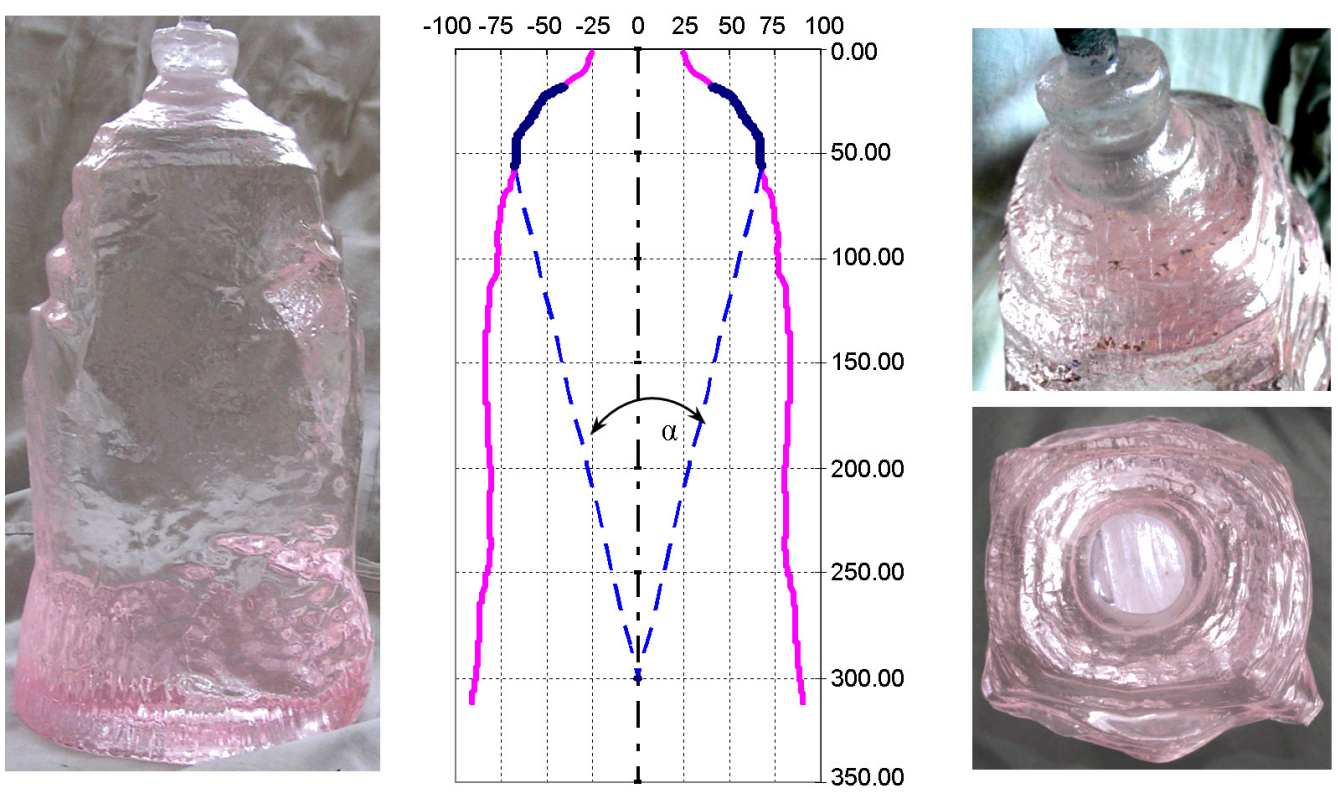

Fig. 4. Crystal profile of sapphire $(24 \mathrm{~kg})$ and crystallization front shape at the end of Stage 2 determined by dynamical analysis of the experimental process.

$h_{(i)}^{*}=h_{(i-1)} \cdot\left(\operatorname{tg} \frac{\alpha_{(i-1)}}{2} / \operatorname{tg} \frac{\alpha_{(i)}}{2}\right)^{2 / 3}$

correspond to correction of the geometrical parameters of the crystallization front at the change of the CFS parameter (the angle $\alpha)$ at the beginning of the given elementary crystallization step; $\Delta H_{i}=h_{(i-1)}-\delta L_{(i)}+$ $\Delta h_{(i)}-r(i) \cdot \operatorname{ctg}\left(\alpha_{(i)} / 2\right)$ is the change of the melt level in the crucible during the time period $\tau ; \Delta h_{(i)}=v_{c r} \cdot \tau$, the axial increase of the crystal during an elementary crystallization step; $r_{i}, h_{i}$ the crystal radius on the level of the melt surface and the length of the part of the crystal immersed into the melt, respectively; $\rho_{m}, \rho_{c r}$, the density of the melt and the crystal material, respectively; $R_{i}$, the internal radius of the crucible on the level of the mirror melt surface. The dynamics of the change of the readings of the crystal weight sensor is formed by unknown variables $v_{c r}$ (the axial crystallization rate) and the parameter CFS. Therefore, the crystallization process was simulated by the method of iterations.

The functional dependence of the crystal diameter $\left(d_{i}\right)$, the rate of crystallization $\left(v_{c r}, v_{t o p}, v_{p e r}\right)$, the angle at the vertex of the crystallization front $\left(\alpha_{i}\right)$ and the readings of the weight meter $\left(\Delta G_{i}\right)$ on the length of the crystal over the melt $\left(L_{i}\right)$ and the dura- tion of crystallization is determined by the iteration method using the computer program of dynamical calculator "SK Forecast". The said program is developed by "Alyuda Research" company (www.alyuda.com) using C\# and NET 4.0. The nonlinear equation for determination of the crystal radius at each step of iteration is solved by the method of bisection.

Assuming that the calculated crystal profile and the dynamics of the rise of the crystal weight completely correspond to the real data of the grown crystal, one can state that the calculated changes of the rate of crystallization and of the angle $\alpha_{i}$ unambiguously represent the dynamic characteristics of the implemented process. The analysis results are presented graphically and digitally. This makes it possible to analyze the functional relation between different dynamic parameters of the crystallization process and the qualitative characteristics of the grown crystal.

\section{Analysis of dynamic parameters of the crystallization process}

By the described method the dynamic analysis of the crystallization process of sapphire weighing $24 \mathrm{~kg}$ grown along crystallographic direction [10T0] was realized. The grown crystal had a good optical quality and legibly expressed the lateral surface 


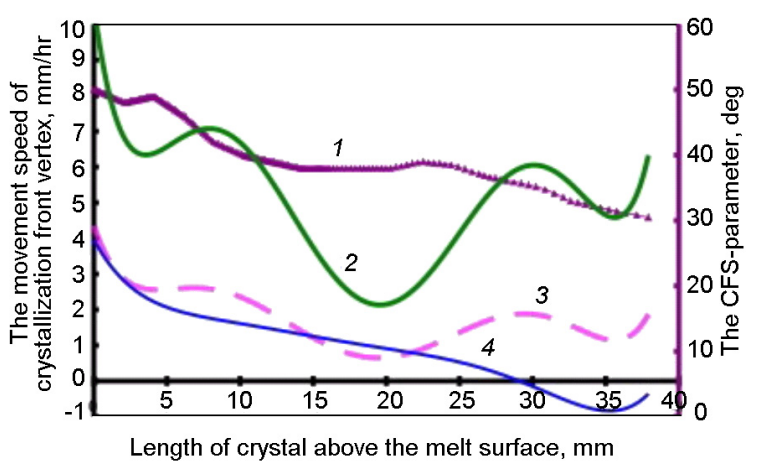

Fig. 5. Dynamics of the change of the crystallization front parameter and of the crystallization speed defined by dynamical analysis of the crystallization process: 1 - the shape parameter of a crystallization front (CFS-parameter); 2 - the movement speed of crystallization front vertex $\left(v_{c r}\right) ; 3$ - the crystallization speed at top of crystallization front $\left(v_{\text {top. }}\right) ; 4-$ the crystallization speed on crystallization front periphery $\left(v_{\text {per }}\right)$.

faceting, proper to the crystallographic planes [0001] and [1120] (Fig. 4). The dynamic analysis data allow to conclude that the crystal with a weight of $5615 \mathrm{~g}$ has reached the crucible bottom within $\sim 57 \mathrm{~h}$ of crystallization, the value registered by the weight sensor was $2640 \mathrm{~g}$. The shape of the crystallization front corresponds to the ratio of the effective values of the radial and axial gradients $G(r) / G(l) \approx 2.75$. During this time the CFS-parameter droningly was diminished from $50^{\circ}$ to $31^{\circ}$ (Fig. 5). Such change of the form of crystallization front is accompanied by the value decrease of the normal component of crystallization speed on periphery of the front $\left(v_{p e r}\right)$ that explains forming of proper faceting of the growing crystal.

The lateral surface of crystal began to be formed after that when the crystallization front attained the bottom of crucible (see the Fig. 4). Growth of crystal took place with predominance of the normal component of crystallization speed at the cone top of the crystallization front $\left(v_{t o p} \cdot v_{p e r}\right)$. In this case the crystallization speed along the crystal axis has undulatory change within the limits of $2 . .10 \mathrm{~mm} / \mathrm{hr}$.

Instability of dynamic parameters of a shouldering process (stage 1) causes forming of resilient tensions and, accordingly, generation of blocks structure of the growing crystal. The technological cause of instability on the initial stage of process is disparity of the decline rate of power on a heater and intensity of crystallization heat removal from the formed crystal. The growth equipment has characteristic features, therefore for the steady dynamics of crystallization is needed the correction of decline rate of the power on a heater individually for the every growth setting.

It is possible to determine the individual characteristic for the every growth equipment by the method of dynamic analysis and take into account it for the definition of the operating practices of 1 st and $2 \mathrm{nd}$ stage of the crystallization process. The certain sequence of technological operations allows taking into account the features of technological equipment and optimizing the thermal conditions of process of crystallization (Fig. 6).

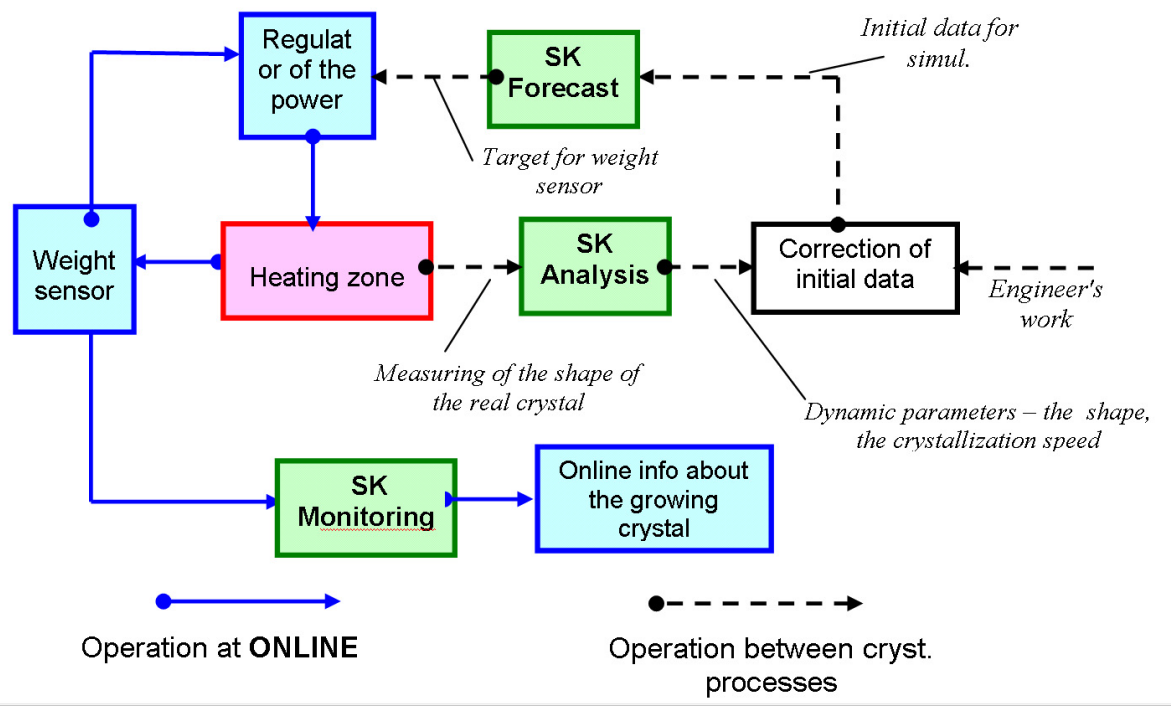

Fig. 6. The scheme of analysis and control of sapphire crystallization for the KY-method. 
On the basis of analysis of dynamic parameters of the grown crystal the initial data of virtual model are correcting and the crystallization speed are optimizing [9]. During optimization of these parameters, are determining the pulling speed of crystal from melt and the time history of the crystal weight for next crystallization process. These descriptions as the initial data are used for conducting of a next crystallization. The regulator of power will realize the set dynamics of change of weight of growing crystal on the basis of registration of the weight sensor and the shape of the crystal will is formed by the set change of speed of its drawing out from melt.

\section{Conclusions}

Thus, the dynamic analysis makes it possible to correct the conditions of subsequent crystallization processes taking into account the quality of the grown crystal. The offered analysis of the real crystallization processes can be used for optimization of growing of different crystals by the Kyropoulos method. The Korean colleagues of the LG-Siltron firm in accordance with our recommendations tested this method at growing of sapphire weighing $85 \mathrm{~kg}$ [10].

\section{References}

1. S.E.Demina, E.N.Bystrova, M.A.Lukanina et al., J.Opt. Mater., 30, 62 (2007).

2. S.E.Demina, V.V.Kalaev, J.Cryst. Growth, 320, 23 (2011).

3. V.M.Mamedov, S.A.Rukolaine, Math.Modeling, 16, 15 (2004).

4. W.J.Lee, Y.C.Lee, H.H.Jo, Y.H.Park, J. Cryst. Growth, 332, 120 (2011).

5. Zhang Lunyong, Zuo Hongbo, Sun Jianfei et al., Cryst. Res. Technol., 46, 1019 (2011).

6. Zhang Lunyong, Zuo Hongbo, Cao Fuyang et al., Cryst. Res. Technol., 47, 175 (2012).

7. Ie.V.Kryvonosov, D.I.Kryvonosov, P.V.Konevskyi, L.A.Lytvynov, Scientific Program and Book of Abstr.17th Inter. Conf. Crystal Growth and Epitaxy, University of Warsaw, Poland (2013), p.97.

8. B.M.Sinelnikov, A.Yu.Ignatov, O.T.Gudnin, Zh.V.Salo, Abstr. 8th Inter. Conf. "Chemistry of Solid and Modern Micro- and Nanotechnology", the State Technology University of Nordic Caucasus, Kislovodsk-Stavropol, Russia (2008).

9. Patent UA 103465 U (2015).

10. Do Won Song, Kwang Seok Kim, Hyo Kim, Korean J.Chem. Eng., 32, 486 (2015). 